\title{
Virtualização do trabalho durante a Pandemia do COVID-19: avaliação da experiência dos servidores de uma Instituição Federal de Ensino Superior
}

\section{Work virtualization during the COVID-19 Pandemic: evaluation of the experiences of servers at a Federal Institution of Higher Education}

\author{
Suzana Baccili Mestranda em Administração Pública (PROFIAP). Universidade Federal de Alagoas (UFAL) - \\ https://orcid.org/0000-0002-1953-4278 Brasil. suzana.baccili@progep.ufal.br \\ Nicholas Joseph Tavares da Cruz Doutorado em Engenharia de Produção. Universidade Federal de Alagoas (UFAL) - Brasil. \\ http://orcid.org/0000-0003-0765-5424 nicholas.cruz@feac.ufal.br
}

\begin{abstract}
RESUMO
O auxílio das Tecnologias da Informação e Comunicação (TICS) tem propiciado novas formas de trabalho nas organizações, dentre elas o teletrabalho. Com o advento da pandemia da COVID-19 essa modalidade foi adotada por diversos órgãos públicos e empresas privadas de modo a não interromper totalmente suas atividades. Assim, esta pesquisa visa avaliar as percepções dos servidores quanto à excepcional implantação do regime de teletrabalho em uma Instituição Federal de Ensino Superior (IFES) no que diz respeito às vantagens e/ou desvantagens nos âmbitos pessoal, organizacional e social; e verificar a viabilidade de implementação de um Programa de Gestão de Teletrabalho na IFES. Adotou-se como estratégia o estudo de caso de abordagem qualitativa exploratória. Os dados foram coletados através de entrevistas realizadas com 06 servidores lotados dentre os 15 setores classificados como essenciais no Plano de Contingência da IFES. Os resultados foram apreciados pela Análise de Conteúdo de Bardin e identificaram que inicialmente a implantação do teletrabalho não foi percebida de forma positiva, porém, após o período de adaptação, os entrevistados apontaram ganhos como flexibilidade, melhoria na qualidade de vida, produtividade, melhor relacionamento familiar, economia de tempo com deslocamento e motivação. Na visão dos participantes é viável a implementação definitiva do teletrabalho, desde que ocorra de forma planejada e que não prescinda o trabalho presencial. As TICs, cada vez mais presentes e em evidência na pandemia, possibilitaram à Administração Pública uma nova oportunidade de transcender o paradigma da cultura da burocracia pelo da inovação.
\end{abstract}

Palavras-chave: Teletrabalho. Administração Pública. Tecnologias da Informação. COVID-19.

\begin{abstract}
The aid of Information and Communication Technologies (ICTs) has provided new ways of working in organizations, among them teleworking. With the COVID-19 pandemic, this work modality was adopted by several public agencies and private companies so as not to interrupt their activities completely. Thus, this research aims to evaluate the perceptions of employees regarding the exceptional implementation of the telework regime in a Federal Institution of Higher Education (IFES) regarding the advantages and/or disadvantages in the personal, organizational and social spheres; and to verify the feasibility of implementing a Telework Management Program at IFES. The strategy adopted was the case study of an exploratory qualitative approach. The data were collected through interviews conducted with 06 servers from among the 15 sectors classified as essential in the IFES Contingency Plan. The results were assessed by the Bardin Content Analysis and identified that initially the deployment of telework was not perceived in a positive way, however, after the adaptation period, the interviewees pointed out gains such as flexibility, improvement in quality of life, productivity, better family relationship, time saving with no need for commuting, and motivation. In the view of the participants, it is viable to implement telework definitively, as long as it occurs in a planned manner and does not dispense with in-person work. The ICTs, increasingly present, and in evidence during the pandemic, have allowed the Public Administration a new opportunity to transcend the paradigm of the culture of bureaucracy through innovation.
\end{abstract}

Keywords: Telework. Public Administration. Information Technologies. COVID-19. 


\section{INTRODUÇÃO}

As mudanças organizacionais ditadas pelo avanço da inovação tecnológica demandam das instituições públicas e empresas privadas o desenvolvimento de habilidades e competências capazes de reagirem por meio de estruturas e processos de trabalho ágeis, flexíveis e desburocratizados. Tais características se fazem essenciais para orientação de suas estratégias buscando torná-las mais competitivas no meio organizacional.

Embora a administração pública estruturalmente apresente maior rigidez e burocracia, a utilização de ferramentas inovadoras, dentre elas as Tecnologias da Informação e Comunicação (TICs), podem contribuir no processo transformacional dos órgãos públicos vindo a oferecer melhoria do desempenho institucional e modernização dos procedimentos internos de modo a responder com maior agilidade aos anseios da sociedade que cada vez mais exige eficiência, qualidade e otimização dos gastos públicos.

As TICs têm auxiliado as instituições públicas a se tornarem digitais de modo a simplificar o acesso aos serviços públicos e a oferecer mobilidade na execução de suas atividades institucionais para além de suas estruturas físicas, onde o comparecimento do servidor na repartição não é essencial para que o serviço seja prestado, o que tem sugerido a adoção de novas práticas laborais, a exemplo do teletrabalho (LEITE; MULLER, 2017; BROGNOLI; FERENHOF, 2020; MENDES; OLIVEIRA; VEIGA, 2020). Boonen (2002) elenca que a implantação desse regime pode proporcionar maior flexibilidade organizacional impactando na redução dos custos operacionais, no ganho de eficiência e produtividade das áreas e pode aprimorar a gestão de pessoas.

Devido à crise sanitária sem precedentes da pandemia do coronavírus (COVID-19) declarada pela Organização Mundial de Saúde (OMS), em março de 2020, as organizações públicas federais adotaram o teletrabalho, em caráter excepcional, de maneira a dar continuidade às suas atividades seguindo as orientações sanitárias de distanciamento social editadas na Instrução Normativa 19/2020 do Ministério da Economia, que autorizou a utilização desse regime laboral como uma das medidas de prevenção à disseminação da COVID-19 (BRASIL, 2020a). Na rede federal de educação, 95\% da força de trabalho passou a exercer suas atividades por intermédio do teletrabalho (BRASIL, 2020c).

Esse cenário epidemiológico, em prol do distanciamento social, levou à suspensão, por tempo indeterminado, das atividades acadêmicas presenciais em toda a rede de ensino no Brasil, o que culminou por abranger as rotinas acadêmicas e administrativas das Instituições Federais de Ensino Superior (IFES). Objeto desse estudo, a IFES analisada seguiu as orientações adotadas pelo serviço público federal como medida de prevenção à pandemia do coronavírus publicando em seu site institucional um plano de contingência elencando os serviços essenciais e os critérios necessários para o desempenho das tarefas em regime de teletrabalho pelos servidores. Isto posto, essa pesquisa tem o objetivo de analisar as percepções dos servidores quanto à excepcional implantação do regime de teletrabalho na referida IFES buscando identificar vantagens e/ou desvantagens percebidas nos âmbitos pessoal, organizacional e social, e verificar se os servidores visualizam uma possível implementação de um Programa de Gestão de Teletrabalho na IFES.

A pesquisa é relevante visto que pode contribuir para o enriquecimento da temática na área acadêmica principalmente por se tratar de uma abordagem no serviço público, onde a produção se dá de maneira incipiente no cenário nacional (OLIVEIRA; PANTOJA, 2018). Atualmente, o tema também ganhou destaque devido às novas abordagens de trabalho impulsionadas pela pandemia da COVID-19 (BELZUNEGUI-ERASO; ERRO-GARCÉS, 2020).

O artigo está estruturado em cinco partes: esta introdução seguida pelo referencial teórico abordando o desenvolvimento do teletrabalho ao longo dos anos. Em seguida, são apresentados os procedimentos metodológicos, a análise dos resultados e, por fim, algumas considerações.

\section{TELETRABALHO}

Esta seção apresenta os conceitos, os benefícios e os desafios do tema teletrabalho e um breve histórico dessa modalidade no Brasil e na Administração Pública Federal, que serviram de subsídio para o desenvolvimento do presente estudo. 


\subsection{Conceitos, benefícios e desafios}

O teletrabalho tornou-se um fenômeno contemporâneo, apesar de já ser debatido nas últimas décadas nas organizações não sendo um fator totalmente recente (STEIL e BARCIA, 2001; TREMBLAY, 2002). A rotina de não se deslocar diariamente a um local de trabalho específico passou a ser reconhecida, e desde então, novas tecnologias têm surgido para auxiliar as empresas e o teletrabalhador (MELLO, 2011).

A nomenclatura telecommuting ou home office foi inicialmente apresentada por Nilles, considerado um dos pioneiros no estudo do teletrabalho. A ideia proposta na década de 1970 foi a de um projeto com o objetivo de levar o trabalho ao trabalhador com a utilização de meios tecnológicos (FILARDI; CASTRO; ZANINI, 2020; LÓPEZ-IGUAL e RODRÍGUEZ-MODROÑO, 2020). Tal movimento possibilitaria a economia de recursos não renováveis em resposta à crise energética da época (BAILEY; KURLAND, 2002; MELLO, 2011).

Alguns autores utilizam como sinônimos de teletrabalho as nomenclaturas telework, telecommuting e e-commuting (NOGUEIRA; PATINI, 2012; ROCHA; AMADOR, 2018). Essas distintas denominações têm como principais características comuns a flexibilização dos locais de trabalho e, algumas vezes, do tempo a ele empregado utilizando as TICS para desenvolvimento das atividades e ampliando as fronteiras organizacionais (COSTA, 2005; ROCHA; AMADOR, 2018).

Mello (1999) define que o teletrabalho substitui de forma parcial ou total as viagens diárias de idas e vindas à organização por tecnologias de informação com auxílio de computadores e outros equipamentos disponíveis no mundo do trabalho, tais como fax, notebook, equipamentos de teleconferência, telefone fixo e celulares.

Para Boonen (2002) o teletrabalho pode ser definido como a modalidade de trabalho desenvolvida remotamente externa à organização por intermédio das TICs que, dada sua natureza, não se consideram como trabalho externo. Caracterizado por sua capacidade de ser flexível em tempo e espaço, não sendo necessário o desempenho das funções dentro do escritório, o teletrabalho representa a mudança de uma geografia de trabalho comumente aceita envolvendo as dimensões social, cultural, econômica, ambiental, legal, tecnológica, organizacional e os diversos atores envolvidos (SAKUDA; VASCONCELOS, 2005).

A Sociedade Brasileira de Teletrabalho e Teleatividades (SOBRATT), conceito usado neste estudo, define que:

O Teletrabalho ou trabalho remoto, significa literalmente, trabalho à distância. Concretamente, trata-se de uma forma de trabalho que é realizada fora do escritório da empresa ou em domicílio, de maneira integral ou periódica, através das chamadas tecnologias móveis (Ex.: Internet, Celulares, Smartphones, Notebooks, Tablets) (SOBRAT, 2020).

O teletrabalho surge como opção às organizações que buscam se aperfeiçoar adaptando-se às mudanças, tais como a redução dos custos operacionais, o avanço das tecnologias, a flexibilização dos processos de trabalho, promoção da autonomia e do amadurecimento profissional para os que ingressam no mercado, bem como os reflexos que esse modelo pode proporcionar na vida dos colaboradores (ADERALDO; ADERALDO; LIMA, 2017; OLIVEIRA; PANTOJA, 2018).

Além dos benefícios para a organização, o teletrabalho também pode impactar positivamente na qualidade de vida do colaborador ao oferecer vantagens como maior autonomia, motivação, produtividade, flexibilidade de horário, redução do custo com transporte e alimentação e maior interação com a família (VALENCIA, 2018). Os reflexos na sociedade podem ser percebidos na melhoria da mobilidade dos espaços urbanos e dos índices de poluição (HAU; TODESCAT, 2018; FILARDI; CASTRO; ZANINI, 2020).

No entanto, apesar de serem diversas as vantagens, por outro lado, existem desafios nessa modalidade que não podem ser negligenciados. Fatores como isolamento social, controle por resultados, nova cultura organizacional e de gestão de pessoas, utilização de ferramentas eficientes de comunicação entre servidor e organização e o interesse do servidor em realizar o teletrabalho devem ser considerados. Há nesse contexto uma mudança na mentalidade de gestores, equipe e organização (SILVA, 2015; OLIVEIRA; PANTOJA, 2018). 
São apresentados no Quadro 1 os benefícios e as contrariedades que podem advir do trabalho remoto para as dimensões organizacional, do teletrabalhador e a da sociedade.

Quadro 1-Vantagens e desvantagens do teletrabalho

\begin{tabular}{|c|c|c|c|}
\hline & Autores & Vantagens & Desvantagens \\
\hline \multirow[t]{3}{*}{ 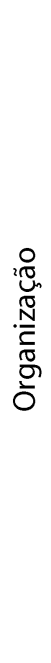 } & $\begin{array}{l}\text { Boonen (2002); } \\
\text { Rocha e Amador } \\
(2018)\end{array}$ & $\begin{array}{l}\text { Redução dos custos fixos com } \\
\text { espaço físico, equipamentos e } \\
\text { manutenção; } \\
\text { Redução dos riscos com acidentes } \\
\text { de trabalho; } \\
\text { Ganhos em produtividade } \\
\text { associados à motivação; } \\
\text { Diminuição do absenteísmo; } \\
\text { Aumento da flexibilidade } \\
\text { organizacional. }\end{array}$ & $\begin{array}{l}\text { Perda da identidade organizacional provocada } \\
\text { pela ausência de comunicação entre o indivíduo e } \\
\text { a organização. }\end{array}$ \\
\hline & Pinel (2012) & $\begin{array}{l}\text { Em caso de catástrofes as atividades } \\
\text { não são suspensas. }\end{array}$ & $\begin{array}{l}\text { O desenvolvimento do trabalho é fortemente } \\
\text { dependente de tecnologia. }\end{array}$ \\
\hline & $\begin{array}{l}\text { Hau e Todescat } \\
\text { (2018) }\end{array}$ & $\begin{array}{l}\text { Maior motivação; } \\
\text { Aumento da produtividade. }\end{array}$ & $\begin{array}{l}\text { Necessidade de tecnologias específicas e a } \\
\text { vulnerabilidade dos dados e recursos da } \\
\text { organização. }\end{array}$ \\
\hline \multirow{3}{*}{ 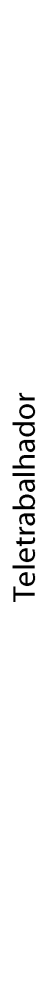 } & $\begin{array}{l}\text { Boonen (2002); } \\
\text { Tremblay (2002); } \\
\text { Estrada (2014) }\end{array}$ & $\begin{array}{l}\text { Criatividade; } \\
\text { Redução do nível de stress; } \\
\text { Flexibilização de horários e a maior } \\
\text { disponibilidade para integração } \\
\text { familiar; } \\
\text { Diminuição de gastos com } \\
\text { deslocamentos, refeições e outros } \\
\text { custos pessoais; } \\
\text { Melhoria na qualidade do trabalho; } \\
\text { Autonomia para organização do } \\
\text { modo de trabalhar. }\end{array}$ & $\begin{array}{l}\text { Sistema do trabalho isolado; } \\
\text { Conflito do espaço privado/familiar e do espaço } \\
\text { profissional; } \\
\text { Não dispor de um ambiente adequado: ambiente } \\
\text { com pouca ventilação, iluminação ou espaço } \\
\text { reduzido; } \\
\text { Falta de comunicação entre a base e o campo } \\
\text { pode se transformar em uma barreira para o } \\
\text { profissional teletrabalhador; } \\
\text { Dificuldade de se motivar ou de se disciplinar; } \\
\text { Dificuldade de concentração quando o ambiente } \\
\text { não é favorável. }\end{array}$ \\
\hline & $\begin{array}{l}\text { Aderaldo, } \\
\text { Aderaldo e Lima } \\
(2017)\end{array}$ & $\begin{array}{l}\text { Avaliação por seu desempenho na } \\
\text { entrega dos trabalhos; } \\
\text { Postura mais proativa; } \\
\text { Planejamento mais ativo de suas } \\
\text { atividades e tarefas; } \\
\text { Desenvolvimento de competências } \\
\text { individuais, tais como } \\
\text { amadurecimento profissional, } \\
\text { responsabilidade, agilidade e } \\
\text { proatividade. }\end{array}$ & $\begin{array}{l}\text { Trabalhar além das horas semanais exigidas por } \\
\text { lei; } \\
\text { Sobreposição do trabalho na vida familiar; } \\
\text { Isolamento social. }\end{array}$ \\
\hline & $\begin{array}{l}\text { Hau e Todescat } \\
\text { (2018) }\end{array}$ & $\begin{array}{l}\text { Qualidade de vida em família; } \\
\text { Otimização do tempo livre. }\end{array}$ & Falta de uma regulamentação. \\
\hline $\begin{array}{l}\frac{\pi}{0} \\
\frac{\pi}{0} \\
\frac{\pi}{2} \\
\stackrel{0}{0}\end{array}$ & $\begin{array}{l}\text { Nilles (1997) } \\
\text { apud Boonen } \\
\text { (2002); } \\
\text { Tremblay (2002); } \\
\text { Rocha e Amador } \\
\text { (2018); } \\
\text { Hau e Todescat } \\
\text { (2018) }\end{array}$ & $\begin{array}{l}\text { Melhoria do meio ambiente e a } \\
\text { menor dependência dos } \\
\text { combustíveis fósseis; } \\
\text { Diminuição da poluição urbana; } \\
\text { Diminuição dos congestionamentos; } \\
\text { do consumo de energia e da } \\
\text { poluição. }\end{array}$ & Não foram apresentadas desvantagens. \\
\hline
\end{tabular}

Fonte: elaborado pelos autores (2020). 


\subsection{Teletrabalho no Brasil e na Administração Pública Federal}

No Brasil o avanço do teletrabalho ganhou força em meados dos anos 90, mas é com o advento da reforma da Consolidação das Leis do Trabalho (CLT) em 2017 que se teve a regulamentação legal do assunto para as relações de trabalho da iniciativa privada.

No serviço público, uma das primeiras experiências de teletrabalho ocorreu no Serviço Federal de Processamento de Dados (SERPRO), em 2005 (MELLO, 2011). Desde então, com a edição de regulamentos próprios, outras experiências dessa modalidade de trabalho foram experimentadas, pelo Tribunal de Contas da União (TCU), pela Advocacia-Geral da União (AGU) e pela Controladoria Geral da União (CGU) servindo de referência para a administração pública e demonstrando que a utilização do teletrabalho apresenta resultados positivos no desempenho das atividades institucionais promovendo maior transparência, aumentando a eficiência na utilização dos recursos públicos, produzindo ganhos na qualidade de vida do servidor participante da modalidade de teletrabalho, dentre outros (SILVA, 2015; OLIVEIRA; PANTOJA, 2018).

$A$ adoção desse regime de trabalho tem ocorrido com maior frequência no setor público de modo a auxiliar na redução de custos, no aumento da produtividade e na otimização do tempo, entretanto, muitos são os desafios a serem transpostos para que essa forma laboral alcance seu potencial pleno (FILARDI; CASTRO; ZANINI, 2020; MENDES; OLIVEIRA; VEIGA, 2020).

Recentemente, impulsionadas pela crise sanitária da COVID-19, a rápida implantação do teletrabalho nas organizações fez o Poder Executivo Federal editar a Instrução Normativa 19/2020 promovendo o uso do teletrabalho, em caráter singular, de modo a dar continuidade às suas atividades. Apesar da experiência em massa de teletrabalho não ter sido planejada, a utilização dessa prática laboral pode ter proporcionado resultados positivos às instituições públicas, mesmo que utilizada em reação à particularidade do momento como mostra um levantamento publicado pelo Ministério da Economia. Nos primeiros quatro meses, em decorrência da pandemia, houve uma economia de $\mathrm{R} \$ 270$ milhões com despesas de diárias e passagens em relação ao mesmo período de 2019 (BRASIL, 2020c).

Os resultados econômicos obtidos nesse período levaram o Poder Executivo a repensar as normas de orientação do teletrabalho e em julho de 2020 houve a regulamentação do tema por meio da Instrução Normativa 65/2020/ME permitindo os ministérios, autarquias e fundações públicas federais a adoção desse regime laboral como uma opção alternativa ao desempenho das atividades organizacionais (BRASIL, 2020b). Se os temores de saúde relacionados à COVID-19 não existissem, as práticas de teletrabalho não teriam sido implementadas de forma massiva (BELZUNEGUI-ERASO; ERRO-GARCÉS, 2020).

\section{PROCEDIMENTOS METODOLÓGICOS}

O contexto do estudo passa-se em uma Instituição Federal de Ensino Superior do Nordeste que possui quatro campi distribuídos em seu estado. Em março de 2020, esse órgão comunicou à sociedade um Plano de Contingência com vistas a mitigar os efeitos do coronavírus em suas instalações e entre as ações adotadas ocorreu a suspensão das aulas presenciais por tempo indeterminado. Quanto aos serviços administrativos, houve a definição de como ocorreria o funcionamento desses enquanto perdurasse o período de pandemia. Nesse plano foram classificados em atividades essenciais 15 setores, sendo eles: os Gabinetes do Reitor e ViceReitor, as Pró-reitorias, os serviços de apoio em segurança e infraestrutura, tecnologia da informação, assessoria de comunicação e os setores responsáveis pelo pagamento de folha de pessoal, de licitação, convênios e contratos. Os servidores com lotação nessas seções desenvolveram suas atividades na modalidade de teletrabalho integral ou parcial, que nessa última abordagem se deu por dias alternados de trabalho presencial e trabalho remoto.

Logo, para o desenvolvimento desta pesquisa adotou-se como estratégia o estudo de caso. Segundo Yin (2005) este tipo de pesquisa investiga um determinado objeto dentro da sua realidade contextual de modo 
a averiguar situações particulares do cotidiano, verificar a maneira que está ocorrendo dada investigação e esclarecer as causas de certo acontecimento.

Sua abordagem é de natureza qualitativa a qual se caracteriza pela singularidade do objeto de estudo, por desvendar fenômenos a partir da ótica do pesquisador considerando o significado que eles trazem consigo e por avaliar o contexto em que o objeto estudado está inserido (NASCIMENTO, 2016). Quanto à sua finalidade, classifica-se como uma pesquisa exploratória, pois foi desenvolvida com o objetivo de revelar as percepções e os pensamentos de um grupo (GIL, 2019). Para a fundamentação teórica foram utilizadas as técnicas de análise bibliográfica e documental.

A escolha dos participantes da pesquisa considerou a vivência relevante e excepcional com a modalidade de teletrabalho em tempo integral ou parcial e se deu pelo critério de conveniência e acessibilidade. Assim, os sujeitos escolhidos para essa pesquisa foram 06 servidores lotados dentre os 15 setores elencados como essenciais no Plano de Contingência da instituição.

Os dados foram obtidos no período de outubro a novembro de 2020, utilizando-se entrevista semiestruturada realizada via videoconferência pela plataforma Google Meet com duração média de 30 a 40 minutos e todas as audiências foram gravadas e posteriormente transcritas. Esse instrumento de coleta de dados se mostrou conveniente para o estudo porque permite identificar o que os entrevistados pensam, avaliam, esperam ou desejam a respeito do assunto pesquisado (MARCONI; LAKATOS, 2017). O roteiro consistia em 13 perguntas as quais buscaram avaliar a percepção dos servidores relativamente à excepcional implantação do regime de teletrabalho na IFES devido ao contexto da COVID-19; identificar as vantagens/desvantagens na percepção dos servidores que adotaram o regime de teletrabalho; e averiguar as expectativas desses servidores quanto à implementação futura de um Programa de Gestão de trabalho remoto pelo órgão.

Para a construção da entrevista foram utilizadas as contribuições dos autores Boonen (2002), Tremblay (2002), Pinel (2012), Estrada (2014), Rocha e Amador (2018), Aderaldo, Aderaldo e Lima (2017) Hau e Todescat (2018) e Filardi, Castro e Zanini(2020), acerca de teletrabalho.

\section{ANÁLISE E DISCUSSÃO DOS RESULTADOS}

O tratamento e a análise dos dados das entrevistas foram conduzidos por meio da análise de conteúdo em consonância com os procedimentos sugeridos por Bardin (2011). De acordo com os conteúdos aferidos nas entrevistas, os dados foram distribuídos em 06 categorias a saber: 1) Implantação do teletrabalho; 2) Escala de trabalho; 3) Comunicação 4) Teletrabalho e vida particular; 5) Aprendizagem organizacional; 6) Sociedade. As falas não foram transcritas em sua totalidade optando-se por apresentar as principais opiniões dadas pelos participantes do estudo.

\subsection{Implantação do teletrabalho}

Os entrevistados informaram que o exercício do teletrabalho foi iniciado em março de 2020 devido à ocorrência da pandemia da COVID-19. A fim de manter seus servidores seguros e mitigar os efeitos da crise de saúde, a IFES proporcionou a execução das atividades por intermédio do teletrabalho. Embora a organização tenha apresentado um Plano de Contingência, os entrevistados não perceberam a preparação da IFES de forma coordenada para a utilização do teletrabalho como apresenta as opiniões de alguns dos entrevistados:

A minha chefia planejou por conta própria, de forma centralizada, e só repassou pra todos, [...] e o critério foi que todos se afastassem do trabalho presencial. Realmente eles tiveram essa preocupação pra não ter a contaminação pelo COVID. (Servidor 5)

Eu nunca me imaginei vivenciando isso, de ter que trabalhar de casa, de tá distante do espaço físico. [...] Não houve nenhum tipo de planejamento, certo?! O que nos forçou "a adotarmos esse regime de teletrabalho" foi a própria pandemia, de modo a manter os 
nossos servidores seguros, sãos. Manter a saúde mental deles e física íntegras. [...] Foi meio que no susto mesmo e a gente foi se adequando conforme a realidade ia se apresentando pra gente. (Servidor 6)

Embora não tenha ocorrido de forma planejada, no atual contexto, o teletrabalho foi uma solução possível para manter, de certa forma, os cidadãos protegidos da COVID-19 e permitir a continuidade dos serviços (BELZUNEGUI-ERASO e ERRO-GARCÉS, 2020).

No processo de implantação, destacou-se na fala dos entrevistados, em sua totalidade, a questão de adaptabilidade ao teletrabalho, embora inicialmente, dada a excepcionalidade da situação, os servidores encontraram dificuldade para se autogerenciar e organizar suas atividades (ESTRADA, 2014):

No começo foi complicado porque eu preciso de rotina de ter as horas pra fazer as coisas senão eu acabo me perdendo. Então eu ficava até em dúvida com relação ao tempo de uma coisa, tempo de outra e dar sequência nas atividades e estabelecer um tempo pra cada uma. Agora tá mais organizado. Eu consigo me organizar melhor. (Servidor 1)

De início eu precisei me adaptar bastante, confesso que não foi fácil, eu precisei me adaptar [...] Quando foi implantado pra gente não foi nada muito bem explicado, você vai trabalhar exatamente oito horas, você vai bater ponto, você vai determinar seu horário pra almoço. Não funcionava desse jeito, era uma coisa muito nova. (Servidor 2)

O teletrabalho requer o uso de TICs e de um espaço físico adequado para seu desenvolvimento (BOONEN, 2002; TREMBLAY, 2002; ESTRADA, 2014). Os entrevistados apontaram que, apesar de possuírem os recursos tecnológicos necessários, eles não detinham, em sua maioria, um ambiente adequado para o desenvolvimento das atividades. Problemas em comum como distrações, barulhos e interrupções dos coabitantes foram apresentados pelos respondentes. Um dos servidores apresentou a necessidade de investir na melhoria do plano de dados de internet para conseguir desenvolver a contento suas atividades:

Olha, de certa forma sim né! Tecnológicos, sim. Eu possuía internet em casa, o computador também. O lugar assim é que é um pouco complicado porque tava com mais gente em casa, na época, mas não era um lugar livre de barulho, livre de intromissão de outras pessoas [...]. (Servidor 1)

Em partes. Eu tinha o notebook, mas no momento da pandemia eu tinha um plano de internet que ele me era suficiente, adequado para as minhas necessidades, mas com o volume das demandas eu não consegui, eu não estava conseguindo atender de modo satisfatório e num prazo razoável participar de reuniões, enfim, com o plano de dados que eu possuía. Aí eu tive que fazer a aquisição de um plano de dados com maior velocidade [...] Eu uso meu quarto, mas têm restrições por exemplo de refrigeração, principalmente durante o dia [...]isso daí é um dos motivos que também eu e alguns colegas até optaram por responder muitas demandas durante o período noturno. (Servidor 4)

Sempre há dificuldade na nossa residência porque tem uma reforma, tem um barulho do vizinho. A gente teve problema aqui em casa com barulho de vizinhos [...] e a divisão no ambiente da casa, [...] não dá pra me concentrar, às vezes, plenamente no serviço (Servidor 5)

\subsection{Escala de trabalho}

Visto que não houve uma definição por parte da IFES em determinar de forma regulamentar em que parte do dia os servidores desenvolveriam suas atividades, os horários de trabalho foram delimitados pelos próprios entrevistados. Assim, eles tiveram maior flexibilidade para escolha do horário de execução das tarefas apresentando tanto resultados positivos, como a motivação da equipe, quanto negativos, como a identificação de excesso de trabalho e jornadas para além da carga horária (FILARDI; CASTRO; ZANINI, 2020): 
Quando foi implantado pra gente não foi nada muito bem explicado [...]. Então que que acontecia em relação às dificuldades, às vezes eu recebia demanda de noite, eu recebia demanda final de semana, de madrugada, obviamente eu teria a opção de não fazer, porque estava acumulando serviço, eu fazia. Quando chegava no dia útil, digamos assim, no horário comercial né, eu recebia mais. Então havia um certo descontrole em qual é realmente meu horário de trabalhar? [...] com o tempo eu fui me adaptando e essa adaptação foi tão boa que eu pude fluir mais nas minhas metas. (Servidor 2)

A divisão das tarefas é um item importante no teletrabalho. Faz-se necessário dimensionar acertadamente o trabalho de maneira a não sobrecarregar a equipe e proporcionar um acompanhamento adequado do desempenho dos servidores. A maioria dos setores recebem as demandas e as distribuem conforme as atividades de cada servidor:

[...] o que de fato fica mais complicado é essa questão de dar andamento no processo físico porque sempre vai depender de alguém que esteja lá. Então o que acontece, muitas vezes quando é o meu dia de revezamento do setor acaba ficando um trabalho acumulado bem grande no dia porque vou ter que pegar essa demanda toda dos colegas dos outros setores pra imprimir, pra dar sequência no processo físico, né. Mas os outros trabalho tão fluindo. (Servidor 1)

O acompanhamento a gente tá fazendo através do Google Drive, o coordenador do setor que eu estou, ele fez um plano de ação e dividiu as tarefas. (Servidor 3 )

Fica difícil você delegar quando você não sabe qual é a tarefa. A gente acaba centralizando mais. [...] como a gente não tá em diálogo, a gente não sabe o que é prioridade agora, nem sempre tem essas reuniões remotas pra definir [...]e que a gente fosse prestando conta das tarefas via e-mail, via um sistema que eles definiram pra gente mandar as tarefas, enfim foi dessa forma, mas abrangeu todos. Tem um sistema que ele designou pra alimentar tarefas, esse sistema se chama Redmine. (Servidor 5)

\subsection{Comunicação}

A fluidez do trabalho depende de uma boa comunicação entre a equipe e os demandantes do serviço. Os meios mais utilizados para a comunicação foram o WhatsApp e o e-mail institucional. Houve contrapontos nas percepções quanto a melhoria e/ou piora da comunicação dos atores no processo, como segue:

Olha, com certeza ficou mais difícil porque a gente não tá num teletrabalho normal que tem o funcionamento do setor e algumas pessoas estrategicamente funcionam em teletrabalho né [...]então a questão do atendimento fica um pouco precarizado. (Servidor 1)

Uma facilidade foi em relação a rapidez porque através dos procedimentos digitais era basicamente, muitas vezes, instantâneo o encaminhamento, a resposta era mais rápida, não se observava tanto a questão de dia útil ou horário comercial, as respostas fluíam mais [...] Não obstante isso, a gente sabe que as dificuldades eram em relação aos problemas tecnológicos como queda de energia, como queda de internet, como problemas particulares que alguns servidores passavam em suas residências, onde a gente dependia do trabalho daquele servidor e ele ficava inacessível. (Servidor 2)

O estresse é muito grande porque a pressão aumentou muito. A questão do teletrabalho ela traz uma expectativa no usuário que também é diferente do atendimento presencial né. No atendimento presencial o usuário ele tem algumas barreiras pra realizar a solicitação dele [...] com o teletrabalho várias barreiras dessas caíram. Então, ele consegue inserir a solicitação dele de uma forma muito ágil, porém o servidor que vai receber a demanda [...] ele tem os recursos, os mesmos recursos que ele tinha através do atendimento presencial, mas ele não consegue responder ao demandante na mesma velocidade que o demandante fez a solicitação. (Servidor 4)

Eu acho que nem todas as reuniões conseguiram suprir o que a instituição precisava de comunicações, de notas informativas, da gente se manter atualizado. As capacitações não são a mesma coisa, eu acho que perde nesse sentido. (Servidor 5) 
Atualmente a forma de comunicação prioritária tem sido pelo Whatsapp, pelo e-mail institucional, certo?! Tanto com os servidores em teletrabalho [..] quanto com o nosso público. Os pontos negativos é que não dá pra resolver as questões de forma tão rápida, porém o ponto positivo é que tudo fica registrado. (Servidor 6)

\subsection{Teletrabalho e vida particular}

Um dos grandes benefícios profissionais citados foi a percepção unânime quanto à melhoria dos níveis de produtividade e qualidade do trabalho (HAU; TODESCAT, 2018):

Eu consigo me concentrar melhor principalmente em determinadas horas do dia que eu foco e pela não interferência no caso do atendimento presencial, dúvidas. Enfim, a produtividade ela aumentou, mesmo não conseguindo atender a todas as solicitações da maneira como gostaríamos. (Servidor 4)

Foi positivo. Gerou mais produtividade do que eu tinha lá, às vezes da falta de foco lá presencialmente [...] Quando a gente tem um tempo em casa planejado, a gente acaba produzindo mais mesmo. (Servidor 5)

A partir do teletrabalho o que eu tenho observado, muito embora eu não consiga muitas vezes entender e estabelecer limites entre vida pessoal e vida profissional, que tá tudo imerso numa mesma realidade né, dentro da nossa casa, tudo acontecendo digamos que ao mesmo tempo, muito embora tenha esse lado negativo aí, eu tenho observado que o meu nível de concentração ele aumentou, a produtividade também, a qualidade do trabalho muito mais, assim, houve um aumento considerável, e eu consigo me planejar de uma forma mais coordenada. (Servidor 6)

A motivação dos servidores é elencada de modo a considerar a comodidade de executar as atividades em casa evitando a locomoção até a IFES e tendo ganho de tempo na rotina diária. Foi um dos benefícios apresentados por todos os respondentes:

[...] Houve uma melhora no meu desempenho, até mesmo na situação de estresse. Eu sou um servidor que mora longe da IFES [...] apesar de ser na mesma cidade [...]. Como eu utilizo o transporte público, é uma hora pra ir e uma hora pra voltar né, o estresse do trânsito também e tudo aquilo que é correlato [...] Eu tenho maior flexibilidade, eu tenho maior tranquilidade, maior autonomia, maior produtividade estando em teletrabalho. (Servidor 2)

Eu considero que essa questão do trabalho remoto ela me tornou um pouco mais motivado, devido a gente não ter essa obrigação de sair de casa, de chegar lá, de enfrentar problemas estruturais que nós temos na IFES também, e aqui, quer queira quer não, aqui em casa, a gente acaba meio que sendo mais cômodo. Não tem como não dizer que não. E diminui muito a questão da locomoção do trabalho, o cansaço de você tá no trânsito para ir e voltar. (Servidor 5)

As mobilidades de espaço e tempo oportunizadas pelo teletrabalho proporcionam aos teletrabalhadores aprimoramentos na qualidade de vida, nas relações familiares e na flexibilidade temporal para desenvolver atividades de cunho pessoal para além das atividades laborais. Nas falas seguintes os entrevistados apresentam ganhos nessas vertentes:

Algumas coisas que eu faço dia a dia em casa ficou mais fácil de fazer, então é, os serviços domésticos no geral, almoço, que eu gosto de almoçar em casa, então ficou mais confortável pra mim. (Servidor 3)

[...] posteriormente, eu mesmo fui formando meu horário de trabalho [...] a partir do momento onde houve essa organização aí eu posso dizer que tudo fluiu bem e eu pude ter uma melhora da qualidade de vida, um melhor relacionamento com a minha família, com 
minha mãe que é idosa, com a minha esposa, com as outras atividades paralelas que eu faço e isso é muito importante, foi muito importante pra mim [...](Servidor 2)

Eu acho que foi melhor porque a gente acaba tomando café junto, a gente acaba almoçando junto, fazendo um lanche junto. Até o planejamento familiar é melhor porque assim, a gente acaba até economizando mais, sabe?! (Servidor 5)

A equipe em si, ela tá muito mais comprometida com o desenvolvimento das atividades em meio à pandemia [...], eu consigo dentro da minha autonomia, da minha flexibilidade organizar minha rotina de trabalho, dar continuidade aos meus projetos sejam eles pessoais ou profissionais para além da IFES, sabe?! Eu acho que pra equipe em si o resultado tem sido muito positivo [...] a maioria das pessoas do setor estão satisfeitas [...] com o projeto do teletrabalho, com a ideia do teletrabalho. (Servidor 6)

É importante para o servidor delimitar as fronteiras invisíveis entre o lar e o trabalho, que agora é executado dentro da sua residência. Esses limites devem ficar claros para o servidor a fim de evitar extensas jornadas de trabalho e para os corresidentes que necessitam compreender que a organização agora faz parta da configuração do lar (ADERALDO; ADERALDO; LIMA, 2017):

A pessoa tem que ter uma disciplina, né. De estabelecer uma determinada rotina ali, porque em casa apesar de você ter aquele tempo de trabalho a sua presença em casa é diferente, as pessoas veem como você estando em casa, né. No caso as pessoas que compartilham do ambiente. (Servidor 1)

Com relação a quantidade de trabalho, aumentou [...] acho que diminui a concentração em casa em relação ao trabalho em relação ao local de trabalho, a lotação eu acredito que manteve a qualidade do trabalho, eu acho que o que dificultou na questão do aumento da demanda do trabalho. Então esse aumento de demanda é que dificultou um pouco de até ultrapassar o horário, que quando você tá no setor de trabalho é aquela hora e pronto[...] a qualquer momento eu recebia uma demanda e às vezes mesmo eu sem querer responder, mas eu entendia que era um assunto sério, então eu respondia. (Servidor 3)

\subsection{Aprendizagem Organizacional}

As TICs são elementos chaves para a execução do teletrabalho. Nos dados coletados, observou-se que os setores organizacionais se empenharam em promover a utilização de diversos meios tecnológicos para que o funcionamento da organização não ficasse comprometido. Porém, alguns entraves foram citados: um foi a questão da grande dependência de processos físicos. Embora a IFES possua um sistema eletrônico de tramitação de processos, esse não opera de forma integralmente digital o que, de certo modo, dificulta a execução das atividades. O outro foi a necessidade de conhecimento ou de buscar conhecer os meios tecnológicos existentes e propostos para continuidade das tarefas:

Lá a gente imprime e anexa ao processo e dá sequência nesse processo físico. O que acontece, a gente depende sempre de ter alguém no setor que faça essa tramitação do físico, [...] colocar todos os processos no sistema de fato, toda a tramitação ser eletrônica. [...] A gente tem o sistema, mas não usa ele na totalidade. (Servidor 1)

O melhoramento é a questão da estrutura da universidade, um sistema de processos melhor que seja implantado do que a gente tem atualmente, [...] uma organização mais definida pra trabalhar em casa no primeiro momento não teve. (Servidor 3)

Alguns servidores do órgão não se adaptaram ao trabalho remoto, em grande parte, eu acho quase a totalidade as pessoas mais idosas tiveram dificuldades em se adaptar às alternativas que nós criamos pra poder desenvolver esse trabalho porque muitas dessas alternativas elas não estavam sendo feitas na forma presencial e são pessoas que já não estão tão atualizadas com novas tecnologias e tudo o mais [...] isso daí fez com que a equipe do setor, a equipe mais jovem ficasse muito sobrecarregada [...] a equipe está no limite da resposta que consegue operar e também alguns recursos que faltaram como, por exemplo, tokens. (Servidor 4) 
Os processos de trabalho de certa forma puderam ser revistos e reorientados para atingirem seus objetos. Diagnosticou-se que a utilização das TICs otimizou a execução das atividades, bem como propiciou um melhor gerenciamento das demandas dos setores.

Foi uma prática positiva porque eu acredito que é uma quebra de paradigmas, principalmente no serviço público. Eu acho que ela é muito positiva, eu acho que ela deveria ser estudada, deveria ser desenvolvida com protocolos [...] não só o teletrabalho, mas o atendimento remoto mesmo com os servidores presencialmente na instituição [...]. Tivemos muitos avanços em relação ao atendimento não presencial, mesmo com todas as dificuldades, com falta de recursos, com explosão de demanda, mas de fato foi uma quebra de paradigma, inclusive nós apresentamos essa possibilidade, no caso para o Pró-reitor do setor, pra verificarmos a possibilidade nos estudos, pra mantermos o atendimento online, pra que seja um atendimento padronizado. (Servidor 4)

Eu acho que em termos de resultado, a gente teve um resultado melhor talvez em termos de resultados positivos. Por quê? Porque no atendimento presencial o setor precisava estar perto das pessoas e às vezes as pessoas não tinham tempo de estar perto. Como eu percebi que a central de atendimento passou a receber muito mais atribuição via e-mail, via telefone e isso foi capitalizado melhor, foi computado no sistema, a gente tá computando melhor cada problema, isso gera indicadores melhores, a gente acaba acompanhando melhor. (Servidor 5)

Um dos adventos negativos do teletrabalho é o isolamento social (ROCHA; AMADOR, 2018), que embora necessário para o contexto, faz o servidor ter um sentimento de distanciamento da organização e de pertencimento do coletivo institucional (BOONEN, 2002):

[...] as perdas eu acho que foi na questão do calor humano mesmo. A gente sente falta das pessoas né?! Sente falta de conversar, sente falta de se manter em dia. (Servidor 5)

A perda da convivência com os colegas de trabalho. Você perde meio que uma referência, sabe?! (Servidor 6)

A redução de custos é um dos maiores benefícios que o teletrabalho pode proporcionar para a organização (BOONEN, 2002; ROCHA; AMADOR, 2018):

Acredito que a questão de economia. Eu imagino que tenha tido uma economia em relação a questão de custeio, de energia elétrica, até de insumos assim digamos de material de limpeza [...] mas certamente telefone, internet, energia elétrica e insumos de limpeza. (Servidor 1)

Ela teve benefício de recursos [...] a questão econômica. (Servidor 3)

Novos processos de trabalho podem gerar resultados positivos para a organização. Quando questionados sobre uma possível implementação definitiva do teletrabalho, os servidores, em sua maioria, conseguem enxergar a continuidade da modalidade de maneira híbrida em que o trabalho presencial e o teletrabalho atuem um paralelo ao outro. Um entrevistado, de maneira antagônica, fez uma observação importante quanto à sua percepção sobre a IFES não vislumbrar a adoção definitiva desse regime de trabalho:

Sinceramente eu não sei se a organização está aberta para esse olhar [...] porque por exemplo [...], quando a gente vai olhar para outras universidades muitas já estão em um outro patamar [...], já designaram comissões, eles já vêm estudando a possível implantação de um teletrabalho. A IFES não deu nenhum primeiro passo, é como se nós não estivéssemos abertos a isso, não estivéssemos de olhos atentos para os benefícios desse teletrabalho [...] ao invés de tá defendendo essa bandeira, olhando atentamente para esse novo movimento, pra essa nova forma de trabalhar é como se isso nunca tivesse existido. (Servidor 6) 


\title{
4.6 Sociedade
}

O teletrabalho não atua apenas dentro das organizações. Ele pode impactar nas relações sociais de modo a diminuir a poluição ambiental, melhorar a mobilidade urbana, dentre outros benefícios, que no contexto da IFES é a desburocratização do serviço público (FILARDI; CASTRO; ZANINI, 2020):

\begin{abstract}
Os benefícios estão atrelados à fluidez e rapidez que os meios tecnológicos possibilitem a realização do serviço público, a exemplo do internet banking [...] evitando que as pessoas tenham que se deslocar do conforto da sua residência quando precisam realizar uma atividade ou ter um serviço tão simples que não precisa estar lá de uma forma presencial, são grandes benefícios. Malefício é se a pessoa ficar dependente e refém dos meios tecnológicos pra poder ter o atendimento ao serviço público que necessite [...] então o atendimento presencial ainda é fundamental, nunca pode ser prescindido, é necessário, então ele, pra o teletrabalho funcionar bem, imagino eu em todos os setores da sociedade, ele tem que trabalhar paralelamente com o teletrabalho, não um ou outro, mas tem que, pra haver uma harmonia e um melhor atendimento democrático às pessoas, a junção dos dois. (Servidor 2)
\end{abstract}

\begin{abstract}
Se a atividade de teletrabalho for bem implementada eu acredito que ela oferece transparência, no caso pro contribuinte em relação às atividades que estão sendo desenvolvidas pelo servidor público existem controles informatizados pra poder aferir essa produtividade. Acredito também que haja uma melhoria, uma otimização em relação aos prazos, uma desburocratização também quanto ao encaminhamento das solicitações. Eu vejo, eu acredito que seria muito positivo a implementação, uma implementação efetuada com estudo, com cautela também, com muito planejamento. (Servidor 4)
\end{abstract}

Eu acho que eu consigo enxergar maiores benefícios pra sociedade quando a gente tem um trabalho híbrido [...] a questão do mundo digital, quem tá precisando do serviço da IFES não precisar se deslocar a um local tão distante da sua residência, via remoto você poder atingir seu objetivo que você quer, seu atendimento e eu acho que deu certo em muita coisa. (Servidor 5)

\section{CONSIDERAÇÕES FINAIS}

O avanço das TICs tem proporcionado mudanças organizacionais por meio de novas formas laborais, dentre elas o teletrabalho que tem sido uma prática organizacional crescente nas últimas décadas. O contexto da crise da pandemia da COVID-19 acelerou o processo de implementação do teletrabalho nas organizações e foi um facilitador para atendimento dos protocolos de saúde que orientam para o distanciamento social. Dessa forma, optou-se no Poder Executivo Federal, em caráter excepcional, a adoção do regime de teletrabalho, o que possibilitou a continuidade dos serviços públicos essenciais. A gestão da IFES estudada, seguiu as orientações gerais do governo quanto ao trabalho remoto.

Desse modo, buscou-se avaliar nessa pesquisa quais foram as percepções dos servidores quanto à implantação do regime de teletrabalho na IFES estudada; se os servidores perceberam vantagens e/ou desvantagens nos âmbitos pessoal, organizacional e social com tal prática laborativa; e se os servidores conseguem visualizar a viabilidade de adoção de um Programa de Gestão de Teletrabalho na IFES.

Inicialmente, a implantação do teletrabalho não foi percebida de forma positiva, pois, de maneira geral, os servidores não observaram uma ação coordenada da IFES, ficando ao encargo de cada chefia, e até mesmo do próprio servidor organizar sua rotina laboral, o que, em um primeiro momento, fez com que eles percebessem uma desorganização e um aumento na carga de trabalho.

Após o período de adaptação, os entrevistados apontaram ganhos como flexibilidade, melhoria na qualidade de vida, aumento na produtividade, melhor relacionamento familiar e motivação com o teletrabalho. A questão do deslocamento casa $x$ IFES foi bastante citada considerando um benefício porque o tempo gasto no trânsito é um fator de estresse e de perda desse tempo, que passou a ser mais bem utilizado. A organização teve ganhos quanto ao aumento da produtividade do servidor, o empenho desses em utilizar novas tecnologias a fim de permitir a continuidade dos serviços, economia de recursos e uma nova visão 
quanto à possibilidade de melhorar os processos de trabalho. Observou-se também que a sociedade pode ser beneficiada com a desburocratização dos serviços e no quesito da mobilidade urbana.

Quanto à uma futura adoção definitiva desse trabalho, os servidores acreditam ser possível a continuidade do teletrabalho de modo que o trabalho presencial não seja prescindido e que haja um planejamento e estudo da forma como ocorrerá sua implementação e o seu gerenciamento. A tecnologia, cada vez mais presente e em evidência na pandemia, propiciou à Administração Pública uma nova oportunidade de transcender o paradigma da cultura da burocracia pelo da inovação. Vale salientar que um servidor pontuou, pertinentemente, que a gestão da IFES parece não estar aberta a esse novo olhar.

Por ser um estudo de caso, os resultados obtidos permitem uma avaliação particular no contexto da IFES não possibilitando assim, fazer generalizações para outras organizações. Porém, a pesquisa contribui de forma significativa para a temática abordada, visto que as produções acadêmicas referente ao teletrabalho em órgãos públicos, em especial nas IFES, permitem investigações acerca desse tema. Para um aprimoramento dos estudos na área, sugere-se a verificação em outras instituições públicas, bem como o acompanhamento do teletrabalho em período longitudinal e pós pandemia.

\section{REFERÊNCIAS}

ADERALDO, Igor Leal; ADERALDO, Carlos Victor Leal; LIMA, Afonso Carneiro. Aspectos críticos do teletrabalho em uma companhia multinacional. Cad. EBAPE.BR, Rio de Janeiro, v. 15, n. spe, p. 511-533, set. 2017.

BAILEY, Diane. E., KURLAND, Nancy. B. A review of telework research: Findings, new directions and lessons for the study of modern work. Journal of Organizational Behavior, 23 (Speclssue), 383-400, 2002. DOI: 10.1002/job.144. Disponível em:

https://www.researchgate.net/publication/227644764_A_Review_of_Telework_Research_Findings_New_Dir ections_and_Lessons_for_the_Study_of_Modern_Work. Acesso em: 31 jul. 2020.

BARDIN, Laurence. Análise de conteúdo. São Paulo: Edições 70, 2011.

BELZUNEGUI-ERASO, Angel; ERRO-GARCÉS, Amaya. Teleworking in the Context of the Covid-19 Crisis. Sustainability, 12, no. 9: 3662, 2020. DOl: 10.3390/su12093662. Disponível em: https://www.researchgate.net/publication/341080024_Teleworking_in_the_Context_of_the_Covid19_Crisis/link/5eac512045851592d6afc610/download. Acesso em: 31 jul. 2020.

BOONEN, E. M. As várias faces do teletrabalho. Revista Economia \& Gestão, v. 2, 4-5, p. 106-127, 2002.

BRASIL. Instrução Normativa n 19, de 12 de março de 2020. [2020a]. Disponível em: http://www.in.gov.br/en/web/dou/-/instrucao-normativa-n-19-de-12-de-marco-de-2020-247802008. Acesso em: 30 jul. 2020.

BRASIL. Instrução Normativa n 65, de 30 de julho de 2020. [2020b]. Disponível em: http://www.in.gov.br/en/web/dou/-/instrucao-normativa-n-65-de-30-de-julho-de-2020-269669395. Acesso em: 31 jul. 2020.

BRASIL. Novas regras para o trabalho remoto são anunciadas pelo governo, de 30 de julho de 2020. [2020c]. Disponível em: https://www.gov.br/pt-br/noticias/trabalho-e-previdencia/2020/07/novas-regraspara-o-trabalho-remoto-sao-anunciadas-pelo-governo. Acesso em: 30 jul. 2020.

BROGNOLI, Tainara da Silva; FERENHOF, Helio Aisenberg. Transformação digital no governo brasileiro: desafios, ações e perspectivas. NAVUS - Revista de Gestão e Tecnologia, v. 10, p. 01-10, 2020. DOI: 10.22279/navus.2020.v10.p01-11.989. Disponível em:

http://navus.sc.senac.br/index.php/navus/article/view/989/pdf. Acesso em:01 nov. 2020.

COSTA, Isabel de Sá Affonso da. Controle em novas formas de trabalho: teletrabalhadores e o discurso do empreendimento de si. Cad. EBAPE.BR, Rio de Janeiro, v. 3, n. 1, p. 01-12, mar. 2005. 
ESTRADA, Manuel Martin Pino. Teletrabalho\& Direito: o trabalho a distância e sua análise jurídica em face aos avanços tecnológicos. Curitiba: Juruá, 2014.

FILARDI, Fernando; CASTRO, Rachel Mercedes P. de; ZANINI, Marco Tulio Fundão. Vantagens e desvantagens do teletrabalho na administração pública: análise das experiências do Serpro e da Receita Federal. Cadernos EBAPE.BR, Rio de Janeiro, v. 18, n. 1, p. 28-46, jan. 2020. DOI: 10.1590/1679-395174605. Disponível em: http://www.scielo.br/scielo.php?script=sci_arttext\&pid=S1679-39512020000100028\&lng=en\&nrm=iso. Acesso em: 30 jul. 2020.

GIL, Antônio Carlos. Métodos e Técnicas de Pesquisa Social. 7. ed. São Paulo: Atlas, 2019.

HAU, Francieli. TODESCAT, Marilda. O Teletrabalho na Percepção dos Teletrabalhadores e seus Gestores: Vantagens e Desvantagens em um Estudo de Caso. NAVUS - Revista de Gestão e Tecnologia, v. 8, n. 3, p. 37-52, 2018. DOI: 10.22279/navus.2018.v8n3.p37-52.601. Disponível em:

http://navus.sc.senac.br/index.php/navus/article/view/601. Acesso em: 30 jul. 2020.

LEITE, Ana Luiza; MULLER, Isabela Regina Fornari. Teletrabalho no serviço público: Estudo de Caso no Ministério Público de Santa Catarina - MPSC. In: SEMINÁRIO EM ADMINISTRAÇÃO, 20., 2017, São Paulo - SP, 2017. Anais [...] São Paulo, SP: USP, 2017.

LÓPEZ-IGUAL, Purificación; RODRÍGUES-MODROÑO. Who is Teleworking and Where from? Exploring the Main Determinants of Telework in Europe. Sustainability, 2020, 12. DOI: 10.3390/su12218797. Disponível em: https://www.mdpi.com/2071-1050/12/21/8797. Acesso em: 01 nov. 2020.

MARCONI, Marina de Andrade; LAKATOS, Eva Maria. Fundamentos de Metodologia Científica. 8. ed. São Paulo: Atlas, 2017.

MELLO, Álvaro. Teletrabalho (Telework): O Trabalho em Qualquer Lugar e a Qualquer Hora. Rio de Janeiro: Qualitymark, 1999.

MELLO, Álvaro Augusto Araújo. O uso do teletrabalho nas empresas de call center e contact center multiclientes atuantes no Brasil: Estudo de caso para identificar as forças propulsoras, restritivas e contribuições reconhecidas. 2011. 268 f. Tese (Doutorado em Administração) - Universidade de São Paulo, São Paulo, 2011. DOI: 10.11606/T.12.2011.tde-16082011-154156. Disponível em: https://www.teses.usp.br/teses/disponiveis/12/12139/tde-16082011-154156/pt-br.php. Acesso em: 30 jul. 2020.

MENDES, Ricardo Augusto de Oliveira; OLIVEIRA, Lucio Carlos Dias; VEIGA, Anne Gabriela Bastos. A viabilidade do teletrabalho na administração pública brasileira. Brazilian Journal of Development, v. 6, n. 3, p. 12745 12759, 2020. DOI: 10.34117/bjdv6n3-222. Disponível em: https://www.brazilianjournals.com/index.php/BRJD/article/view/7725/6698. Acesso em: 30 jul. 2020.

NASCIMENTO, F. P. Metodologia da Pesquisa Científica: teoria e prática - como elaborar TCC. Brasília: Thesaurus, 2016. Disponível em: http://franciscopaulo.com.br/arquivos/Classifica\%C3\%A7\%C3\%A3o\%20da\%20Pesquisa.pdf. Acesso em: 19 fev. 2020.

NOGUEIRA, Analdo Mazzei; PATINI, Aline Campos. Trabalho remoto e desafios dos gestores INMR - Innovation \& Management Review, [S. I.], v. 9, n. 4, p. 121-152, 2012. Disponível em: https://www.revistas.usp.br/rai/article/view/79292. Acesso em: 17 ago. 2020.

OLIVEIRA, Míriam Aparecida; PANTOJA, Maria Júlia. Perspectivas e desafios do teletrabalho no setor público. In: CONGRESSO INTERNACIONAL DE DESEMPENHO DO SETOR PÚBLICO, 2., 2018, Florianópolis. Anais eletrônicos [...]. Florianópolis: Universidade do Sul de Santa Catarina - UNISUL; Universidade Federal de Santa Catarina - UFSC; Universidade do Estado de Santa Catarina - UDESC; Fundação Ena Escola de Governo, 
2018. Disponível em: http://www.cidesp.com.br/index.php/lcidesp/2cidesp/paper/view/481. Acesso em: 19 ago. 2020.

PINEL, Maria de Fátima de Lima. Teletrabalhador. 2012. Disponível em: http://www.teletrabalhador.com/index.html. Acesso em: 5 nov. 2020.

RICHARDSON, Roberto Jarry. Pesquisa Social: métodos e técnicas. 3. ed. São Paulo: Atlas, 2012.

ROCHA, Cháris Telles Martins da; AMADOR, Fernanda Spanier. O teletrabalho: conceituação e questões para análise. Cad. EBAPE.BR, Rio de Janeiro, v. 16, n. 1, p. 152-162, jan. 2018. DOI: 10.1590/1679-395154516. Disponível em: https://www.scielo.br/scielo.php?script=sci_abstract\&pid=S167939512018000100152\&lng=en\&nrm=iso\&tlng=pt. Acesso em: 30 jul. 2020.

SAKUDA, Luiz Ojima; VASCONCELOS, Flávio de Carvalho. Teletrabalho: desafios e perspectivas. Organ. Soc., Salvador, v. 12, n. 33, p. 39-49, jun. 2005. DOI: 10.1590/S1984-92302005000200002 Disponível em: https://www.scielo.br/scielo.php?script=sci_arttext\&pid=S1984-92302005000200002. Acesso em: 30 jul. 2020.

SILVA, Aimée Mastella Sampaio da. A aplicação do teletrabalho no serviço público brasileiro. In: CONGRESSO INTERNACIONAL DE DIREITO E CONTEMPORANEIDADE, 3., 2015, Santa Maria. Anais [...]. Santa Maria: Universidade Federal de Santa Catarina, 2015.

SOBRATT - Sociedade Brasileira de Teletrabalho e Teleatividades. Questões. Disponível em: http://www.sobratt.org.br/index.php/certificacao/questoes/. Acesso em: 23 out. 2020.

STEIL, Andréa Valéria; BARCIA, Ricardo Miranda. Um modelo para análise da prontidão organizacional para implantar o teletrabalho. Revista Administração, v. 36, n. 1, p. 74-84, mar. 2001.

TREMBLAY, Diane-Gabrielle. Organização e satisfação no contexto do teletrabalho. Rev. adm. empres., São Paulo, v. 42, n. 3, p. 54-65, set. 2002. DOI: 10.1590/S0034-75902002000300006

Disponível em: https://www.scielo.br/scielo.php?script=sci_arttext\&pid=S0034-75902002000300006. Acesso em: 30 jul. 2020.

VALENCIA CATUNTA, Ana Maria Cecilia. Aspectos regulatorios del teletrabajo en el Perú: análisis y perspectivas. Rev. IUS, Puebla, v. 12, n. 41, p. 203-226, jun. 2018.

YIN, Robert K. Estudo de Caso: planejamento e métodos. 3. ed. Porto Alegre: Bookman, 2005. 